\title{
2012/1
}

Rethinking regulatory capture

Per J. Agrell and Axel Gautier

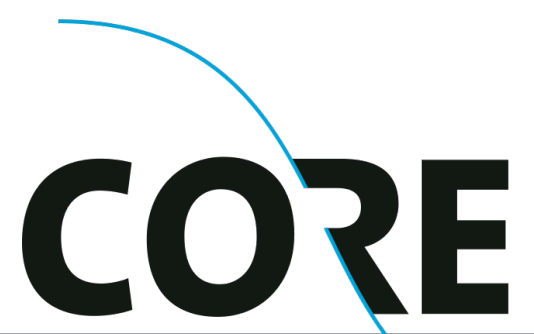

DISCUSSION PAPER

Center for Operations Research and Econometrics

Voie du Roman Pays, 34 B-1348 Louvain-la-Neuve Belgium http://www.uclouvain.be/core 


\title{
CORE DISCUSSION PAPER \\ $2012 / 1$
}

\section{Rethinking regulatory capture}

\author{
Per J. AGRELL ${ }^{1}$ and Axel GAUTIER ${ }^{2}$
}

January 2012

\begin{abstract}
Conventional capture models rely on the idea that regulator is induced to lenient behavior by the regulated firm through offers of monetary transfers, the bribery model, or future employment, the revolving doors model. To avoid socially costly capture, the political principal should then either implement collusion-proof mechanisms through the delegation of welfare gains, or severely restrict the career paths of regulatory staff. The paradox of capture is that neither the two modes of capture, nor the remedy are commonly found in practice. This paper proposes to rethink capture based on the widespread use of industry-commissioned consultants, experts and lobbyists that produce information for regulatory and policy use. A small model (Agrell and Gautier, 2010) introduces a 'soft capture' concept based on a self-enforced collusion between the firm and regulator, linked to the role of the regulator as information-processing intermediate for the political principal. The firm puts processed but biased information at the free disposal of the regulator, 'no strings attached', who can then either use the submitted information or produce a more accurate information by a costly process. Under a set of mild conditions, the equilibrium involves soft capture and the regulator uses the submitted information, leading to some distortions in welfare. A case study of the Occupational Safety and Health Administration (OSHA) in USA serves to motivate and illustrate the model. As shown by the case, the soft capture model may have a stronger positive potential than the conventional models, also implying that policy advice based on it may be valuable.
\end{abstract}

Keywords: regulation, capture, information

JEL Classification: D72, L51

\footnotetext{
${ }^{1}$ Université catholique de Louvain, Louvain School of Management and CORE, B-1348 Louvain-la-Neuve, Belgium. E-mail: per.agrell@uclouvain.be. This author is also member of ECORE, the association between CORE and ECARES.

${ }^{2}$ HEC-University of Liège, B-4000 Liège, Belgium; Université catholique de Louvain, CORE, B-1348

Louvain-la-Neuve, Belgium. E-mail: agautier@ulg.ac.be
}

The authors would like to thank E. Cantillon, C. Guerriero and participants at the $6^{\text {th }}$ International CRESSE Conference on "Advances in the Analysis of Competition Policy and Regulation" and the ECORE seminar for useful comments and suggestions.

This paper presents research results of the Belgian Program on Interuniversity Poles of Attraction initiated by the Belgian State, Prime Minister's Office, Science Policy Programming. The scientific responsibility is assumed by the authors. 


\section{Introduction}

The design of a regulatory process is a challenging task as it involves complex information economic settings and the participation of many actors: politicians, executive, legislature, supervisors, auditors, regulated firms or industry, customers, taxpayers, trade unions. These stakeholders can be categorized in three groups: [political] decision makers, supervisors and interest groups. With this distinction in mind, the regulatory process can be represented as a three-layer hierarchy with, on the top, the decision maker (the political principal), in the middle the supervisor (the regulatory agency) and on the bottom the regulated firm (see Figure 1[a]). In such a hierarchical organization, the bottom layer has privileged access to key information relevant for decision-making. Regulated firms, for instance, have private information on firm and industry costs, demand characteristics and available technologies. This asymmetry of information reduces the effectiveness of the regulatory process. To fill in the information gap, the political principal appoints a supervisor. The regulatory agency is thus an information gathering intermediate for the political principal who remains in charge of the main regulatory tasks ${ }^{2}$. Performing in this task, the regulatory authority deploys resources, permanent and temporary staff, consultants and experts, in order to collect, process and produce information for policy-making relevant to the regulated sector. Information is valuable for the political principal as it reduces the information rent left to the regulated firm. Improved information quality (precision) reduces the cost of regulating the industry, primarily through a welfare increase by lower downstream prices or higher quality at the expense of (at least some) firms. Effective information gathering by the regulatory authorities is thus essential for an efficient regulatory process.

However, regulatory intervention is not immune to capture. Dal Bó (2006, p. 133) broadly defines capture as "the process through which special interests affect state intervention in any of its form". Applied to industry regulation ${ }^{3}$, capture could be more specifically defined as "the process through which regulated monopolies end up manipulating the state agencies that are supposed to control them" Dal Bó (2006, p. 133). In this paper, we focus on capture of regulatory agencies by the regulated industry they are charged to monitor.

There are different forms of regulatory capture. Estache and Wren-Lewis (2011) distinguish capture of decisions and capture of information. The former corresponds to situations where a firm or an industry directly tries to influence the decision made. The latter corresponds to situations where the industry tries to manipulate the information on the basis of which the decision is made. This distinction echoes another between direct and indirect capture. Direct capture denotes settings where the regulated firm exerts influence over the regulator itself, while indirect capture denotes situations

\footnotetext{
${ }^{2}$ Note that even if the regulator is endowed with some decisional power, like the right to set a price-cap level, many regulatory tasks remain in the hands of the political power: decisions regarding industrial structure, organization and financing of universal service obligations, the industry safety regulation, the quality regulation, the access regulation in network industries, the procedure to allocate new licenses (for instance for the $4 \mathrm{G}$ cellular technology) to cite a few.

${ }^{3}$ Industry regulation encompasses many dimensions such economic, product, technical, quality, safety or environmental regulation of sectors and/or natural monopolies.
} 
where the regulated firm influences the regulator indirectly by manipulating decisionmaking instances ${ }^{4}$ who hold power over the regulated agency. When the regulator is the sole responsible for filling the information gap between the firm and the decision maker, the two distinctions overlap. If one refer to our three layer hierarchy, direct capture encompasses all the activities by the regulated firm to manipulate the information collected and reported by the supervisor, hence a form of capture by information while all the influence activities exerted to modify the principal's behavior are referred to as indirect capture or capture of decision. An additional classification separates illegal (fraud, corruption, extortion) and legal (lobbying, career concerns) influence activities.

\begin{tabular}{l|ll} 
& Indirect & Direct \\
\hline Legal & Lobbying & $\begin{array}{l}\text { Revolving doors } \\
\text { Soft capture } \\
\text { Illegal }\end{array}$ \\
Corruption & $\begin{array}{l}\text { Classical capture }\end{array}$
\end{tabular}

Table 1: A classification of capture activities

Table 1 provides some structure to the classifications. Lobbying by organized interest groups to obtain a favorable decision from a politician is both indirect and legal: Lobbyists try to obtain favors from the political power and not from the regulator by providing information about preferences among the electorate or political alliances. When an interest group uses an illegal mean, for instance a bribe, to obtain a favorable decision from a politician, this can no longer be labeled as lobbying but rather as corruption. Evidences on corruption and lobbying are widespread and highly documented.

For the remainder of the paper, we leave aside indirect capture and focus exclusively on direct capture. In the literature, direct capture has been considered along two complementary lines: the classical view pioneered by the works of Tirole (1986) and Laffont and Tirole $(1991,1993)$ and the revolving doors approach (Che, 1995). In the classical view, capture consists mainly in bribing the regulator for not reporting or misreporting relevant information to the political principal. Capture is envisaged as a phenomenon based on an exchange of favors. The regulator accepts to be lenient with the firm, for instance by leaving the price unchanged in a rate review. In return, the firm rewards the regulator, for instance by offering monetary bribes or any kind of transfer such as access to privileged information (stock/business information) or contracts for services (indirect business). Figure 1[b] schematizes the traditional capture.

The classical view on capture is based on reciprocity. Exchange of favors is organized within an explicit or implicit illegal side-contract between the regulator and the firm. The revolving doors approach of capture is based on the same premises: offering lucrative post-regulatory employment in the regulated sector (revolving doors) can serve as a mechanism for exchanging favors. The prospect of future employment is never explicit during the regulatory term, nor are the conditions or tasks potentially

\footnotetext{
${ }^{4}$ Ministries, other branches of government, legislature, etc.
} 
assigned to the staff. This exchange of favors is hence based on an implicit contract with imperfect enforcement and, as such, it cannot be considered as illegal ${ }^{5}$.

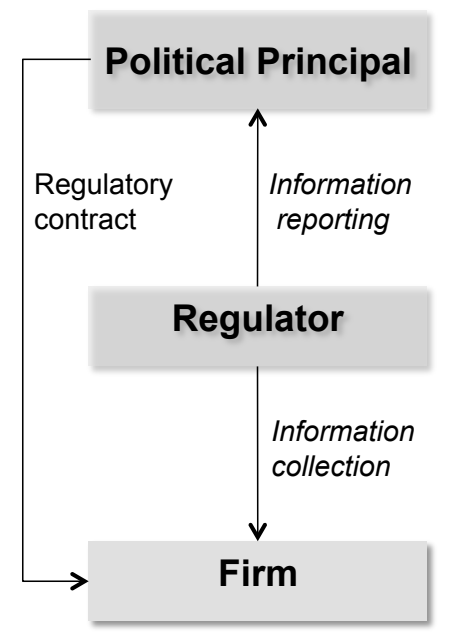

[a]

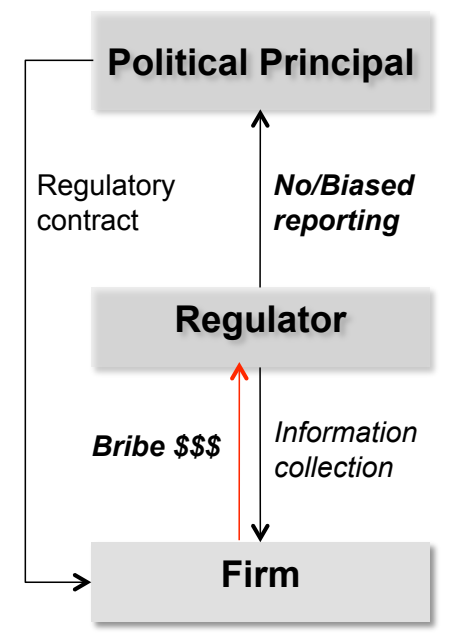

[b]

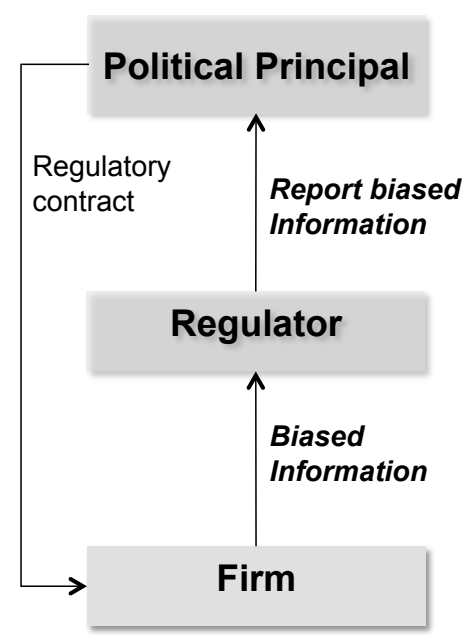

[c]

Figure 1: [a] The three-layer hierarchy, [b] Traditional capture, [c] Soft capture

However, these views of direct capture prove to be unsatisfactory. If the theories were complete, we would observe either widespread direct capture through bribes or revolving doors, or institutions designed to prevent capture to occur ${ }^{7}$. But empirical evidences on regulatory capture in the form of corruption are scarce ${ }^{8}$. Likewise, in-spite of the open revolving doors most regulators turn out to maintain careers in public service or other sectors. Finally, there is no known example of a high-powered incentive scheme for a sector regulator based on industry rent extraction or welfare gains ${ }^{9}$. We thus have a paradox of capture. Neither capture nor its remedy is observed in practice.

We propose an alternative and more intuitive explanation for regulatory capture (see figure $1[c]$ ). To gain influence, the regulated does not need to promise a favor to the regulator. Instead, the regulated firms can influence the regulatory outcome by producing pieces of information relevant for the decision makers and transmit this

\footnotetext{
${ }^{5}$ Notwithstanding, many regulatory authorities have explicit regulations limiting or delaying employment of authority staff in regulated firms, as well as their use of information obtained through their service in the authority. None of these regulations can be said to effectively block the revolving door concerns.

${ }^{7} \mathrm{~A}$ regulatory process is immune to capture when side contracting is non profitable for the parties. Often, it requires the use of specific incentive schemes for the regulatory intermediate to align its objective with those of the political principal.

${ }^{8}$ Note that the difficulty does not primarily reside in the data collection, as the direct capture referred to here only concerns the highest responsible decision maker (the tenured "regulator"). Bribing subordinate staff to obtain favors is ineffective as the regulatory authorities in both theory and practice organize the internal bureaucracy through limited discretion, job rotation and team assignments in order to limit the time and depth of repeated industry interaction.

${ }^{9}$ In reality, most regulators are civil servants with fixed salaries that are publicly known and under restrictions concerning complementary economic activities.
} 
information for free to the regulator ${ }^{10}$. The supervisor receiving a report from the industry has two options: It can either discard it and produce its own report to be transmitted to the political principal or it can copy-paste the industry input and transmit it to the principal. In both cases, the regulator has done its job, but with the later option, it saves time and resources as the information processing has been made by the industry. We argue that accepting industry input is mutually profitable for the regulator and the firm. The regulator because it saves on the information processing cost (or effort). The firm because it controls the content of information used for decision making. Indeed, a firm would agree to transmit information to the regulator only if the decisions resulting from the use of this information turn out to be more favorable than those expected from the internal information processes of the regulator. Information (if any) transmitted by the firm is necessarily biased ${ }^{11}$.

We thus have another mechanism for direct capture that is not based on exchange of favors but rather on mutual interest. This mechanism is different from lobbying as the regulated transmits information to the regulator and not to the politician as in AustenSmith and Wright (1992) ${ }^{12}$. We will refer to this mechanism as soft capture (Agrell and Gautier, 2010). This approach is both direct and legal and we conjecture that this form of capture is quite common in regulated industries; we illustrate that by looking at the example of OSHA, the health and safety regulator in the US in section 4. OSHA can be seen as an example where the regulatory agency develops from an information production intermediary to primarily monitoring in a mechanism based on 'voluntary' or 'self-regulation' by the regulated firms (Shapiro and Rabinowitz, 2000).

\section{The paradox of capture}

\subsection{The classical model of capture}

Consider a standard problem of incentive regulation. The regulated firm supplies goods or services to customers on the behalf of the political principal but the latter is unaware of the firm's production cost. The principal designs an incentive compatible contract for the firm that specifies a quantity to be produced and a transfer to the firm contingent on a cost report made by the firm; A standard problem (see Laffont and Tirole, 1993). At the optimal contract, the efficient firm receives a compensation above its cost of production, the so-called information rent. This rent is socially costly and, in this framework, the regulator is supposed to mitigate the information advantage of the firm by realizing a costly audit of the firm's private cost parameter.

\footnotetext{
${ }^{10}$ Regulated firms have the legal obligation to transmit data to the regulator. Here we do not consider data transmission but information that has already been processed by the regulated firm such as a cost assessments, suggested technical regulations, or a methodologies to benchmark industry performance.

11 We disregard the (hypothetical) case of an altruistic firm e.g. under public ownership. First, empirical evidence suggest that such firms frequently are more inefficient than private firms without taking voluntary action. Second, the managers of the public firm may pursue non-altruistic objectives such as budget maximization or effort minimization, but of which are consistent with the empirical evidence and refusal to submit unbiased information. Third, even if there were no internal incentive problems, a rational altruistic firm would not provide unbiased information processing below cost.

12 When the firm transmits information to the regulator, the later remains the sole source of information for the political principal. Should the firm transmit its information directly to the political principal, it would have two sources of information and it would be able to improve its knowledge of the industry.
} 
If the regulator has some discretion when it reports information collected during its audit to the political principal, the firm is ready to bribe the regulator for not reporting rent-reducing information. This mechanism is at the root of the classical model of capture. It is based on two keys elements: regulatory discretion and information rents.

In Tirole (1986) and Laffont and Tirole (1991), the regulator realizes a costly audit of the firm's unknown cost parameter. The auditing technology is imperfect and the cost is observed with some probability lower than one. The information on the firm's cost is "hard" in the sense that it can be verified by the political principal. Thus, the regulator cannot produce false evidences on the firm's cost but it can hide the relevant piece of information (if any) to the principal. Concealing rent-reducing information is congruent with the regulator's degree of discretion. If the audit is successful and its results reported to the political principal, the regulated looses its information rent. For that reason, the firm may be tempted to bribe the regulator for hiding the results of a successful audit.

The side agreement between the parties may be explicit or implicit but enforcement of the side contract is in any case a non-trivial issue (Tirole, 1986). Administrative rules prohibit monetary transfer from the industry to the regulators, who predominantly are civil servants. Other mechanisms based on trust or reputation (Martimort, 1999) are necessary for the collusion to occur. Such side contracts may thus be costly to write and to enforce which might reduce the scope of capture. In addition, the judicial consequences from detection or delation may be unbalanced between the firm (risking a fine) and the career regulator (risking dishonorable discharge, prison and ruined public career options) making the acceptance of bribes risky and susceptible to future hold-up by the firm.

Facing the possibility of capture, the political principal must either tolerate capture and consequently rethink the role devoted to the regulatory institution, or design a collusion-proof regulatory process that is immune to capture. In Tirole (1986) the political principal decentralizes its objective to prevent collusion and pays a compensation for a successful audit that is at least as big as the perceived value of the bribe paid by the firm ${ }^{14}$. Preventing capture is thus costly for the principal as the cost of appointing a supervisor increases. In practice, regulatory institutions do not seem to be designed to prevent the occurrence of this form of capture as, to our knowledge, few regulators are responsible for the regulatory outcome ${ }^{15}$.

Capture is, by definition, a phenomenon that is difficult to estimate empirically. In a rare attempt to test capture with detailed data from regulatory activities, Smith and Söderberg (2010) found no support for the regulatory capture hypothesis. They focus on the treatment of customer complaints by the Swedish Energy Agency (SEA). The resolution of these complains is delegated to a civil servant that could be either proconsumer or pro-firm but this information is not known ex-ante. The SEA can replace the agent if it believes that her (revealed) preferences are incompatible or non-aligned

\footnotetext{
${ }^{14}$ In most of the models of capture, side-contracting is costly meaning that, when the firm pays $\$ 1$ to the regulator, the latter has less than (the equivalent of) $\$ 1$ in its pocket. Transaction cost of side contracting reduces the possibility of capture.

${ }^{15}$ An exception could be the election of regulators that are thus responsible in front of the voters (see Guerriero, 2011).
} 
with those of the institution, in which case, the agent is re-assigned to another function. Capture in this context would be associated with a higher probability of termination if a agency agent proves to be pro-consumer. The data does not confirm this hypothesis and rather suggest that a bureaucrat that takes pro-industry decisions has a higher probability of being removed compared to a pro-consumer decision-maker.

Anecdotical evidences on capture remain relatively rare. Few regulators have been found guilty of corruption though many have shown sympathies with the industry. Evidences of bribed regulators are relatively inconclusive and the traditional view of capture has weak empirical support.

\subsection{Revolving doors}

The doors between regulatory agencies and the industry are not closed. Many regulators have an industry background (they are coming 'in' the revolving doors). Part of the regulatory staff is also moving 'out' of the revolving doors to a job in industry ${ }^{16}$. Appointing regulator with an industry background is a mean to bring industry specific knowledge to the regulatory agency. Likewise, expertise of former regulators is valuable to the industry that can then minimize the cost of complying with regulations. Che (1995) and Salant (1995) emphasis on the potential incentive effect of the revolving doors that may stimulate acquisition of industry specific human capital. But opening the revolving doors is also a concern as it could bias the regulatory decisions in favor of the industry.

Regulators with an industry background may still look at issues with industry eyes and show sympathy for the view expressed by the regulated. Regulators coming in the revolving doors may identify themselves with the industry with, as consequences, a biased regulation that favors the industry.

Moving out of the revolving doors may also bias regulation. The perspective of posterior employment in the regulated industry may discipline the regulators and lead to proindustry regulations. Regulators may be lenient in applying rules in order to attract attention from the industry and signal their interest for the industry views with the hope of a later career in the industry.

The possibility of a future job in the industry acts like the bribe in the traditional model. It is the reward paid by the industry in return of favors made by the regulator. There are however differences between bribes and post-regulatory employment within the industry. First, there is no need of explicit contract or agreement between parties. The industry could have the tradition and the reputation to reward regulators that behaved well in the past. Capture is based on an implicit and imperfectly enforceable agreement between parties. Second, unlike bribes, it is not illegal to appoint in the industry someone with a regulatory experience. Revolving doors is the legal version of direct capture based on reciprocity.

To our knowledge, there is only one paper that explicitly tests the regulatory bias associated created by the revolving doors. Makkai and Braithwaite (1992) collect data

\footnotetext{
${ }^{16}$ Thatcher (2002) provides evidence on the importance of the revolving doors phenomena in selected
} European countries. 
on site inspections realized in Australian nursing homes. They test whether the degree of regulatory enforcement depends on prior experience in the industry or aspiration to leave to job in the industry. Their study does not confirm the revolving door hypothesis. First, regulatory enforcement records do not depend on prior industry experience. Second, softer inspectors do not have a higher probability of leaving to job in the industry.

The traditional capture and the revolving doors conjecture do not received a strong empirical support and evidences of regulatory capture based on reciprocity remain scare and mainly inconclusive. Lack of support for direct capture means that either regulatory institutions are well-designed and they effectively prevent capture by special interest groups or that capture takes another, possibly more pervasive, form. We have rejected the first hypothesis and we will now examine the second in more detail.

\section{Soft capture}

\subsection{The mechanism of soft capture}

We propose an alternative mechanism for regulatory capture that is not driven by reciprocity but by mutual interest. This mechanism, that we call soft capture, is both direct and legal and it is based on the production of biased information by the firm itself (see Agrell and Gautier (2010) for a formal model). In the three-layer hierarchy, the regulator acts as an information gathering intermediate and production of information is costly. Now suppose that the regulator receives information from the firm. One option available to the regulator is to endorse the information produced by the regulated and present it to the decision maker. In this case, the resources normally devolved to information gathering can be used for another purpose such as monitoring compliance with the rules. A regulator that would use industry input saves resources: the staff that is not used to collect information and draft a report can be used to other regulatory tasks. Regulators are thus likely to accept industry input as substitute to inhouse produced information. This can take many forms from making its own an argument putted forward by a consultancy financed by the industry to endorsing fullyfledge sectorial regulation drafted by the industry itself 17 .

Voluntary disclosure of information by the firm might be strange and counterproductive in a context where the firm benefits from the lack of information of the deciding party. But the alternative consists in having the regulator gathering the information itself, a solution that could be even worse for the firm. Transmission of information to the regulator is a profitable alternative for the firm if (i) regulatory decisions are based on the firm input and (ii) information is biased. This last condition is essential for the soft capture mechanism to work. Firms accept to produce and transmit information only if using this information for regulation benefits to the firm. In other words, industry inputs must be systematically biased. Being regulated on the basis of an information tailored to their need is much more profitable for the industry than being regulated on the basis of an independent information. Thus the information transmitted by the firm to the regulator is necessarily biased. Disclosing on a voluntary basis true information would be foolish for firms as the key for successful regulation is access to information.

\footnotetext{
${ }^{17}$ In 2001 the Swedish energy regulator (STEM) endorsed a detailed voluntary service regulation for the
} quality of electricity distribution, developed by the sector association. 
The soft capture mechanism thus works as follows : the regulated firm transmits biased information to the regulator, the later endorses it and reports industry input to the decision maker. Regulation is ultimately based on information controlled by the firm rather than on information collected by an independent supervisor, which is beneficial to the firm. The mechanism is also profitable for the regulator that saves on information gathering costs. Moreover, accepting and endorsing industry produced information potentially reduces the conflicts between the regulator and the industry, a behavior that might be compatible with the minimal squawk behavior described by Leaver (2009).

Soft capture is not based on threats and rewards: both parties are better off if the regulator rubber-stamps the information produced by the firm instead of producing its own. The regulator comes to the political principal with information (as it is expected to do). The firm, if it transmits less precise information, increases its information rent. Hence, capture benefits both parties without requiring any form of side contracting nor side payments between parties. Thus, there is no smoking gun when the regulator is softly captured by the firm. For that reason, we classified in table 1 soft capture as a direct and legal mechanism. Financing partisan R\&D is obviously not illegal and it is somehow beyond the control of the firm is a lazy regulator uses it instead of realizing its own researches.

\subsection{Implications for regulatory design}

Even if in this mechanism the firm produces information for free and transmits it to the regulator, soft capture is damageable to the political principal and to the welfare. Tolerated soft capture indeed decreases the quality of decision-making because information is less precise and biased but it leaves unchanged the cost of gathering information. Producing detailed information for regulatory purpose is profitable for the firm only if the alternative is a more stringent regulation based on the more precise information produced by the regulatory agency. Essential in this mechanism is the presence of the regulator as a 'threat' to extract the biased information from the firm. Should this threat disappear, the firm will no longer produce information ${ }^{18}$.

Maintaining a regulator, even if it only rubbers-stamp the industry proposals, is essential to benefit from information for regulatory design. Absent the middle-layer in the hierarchy, there is no information at all going from the industry to the top-layer. Firms have incentives to softly capture the regulator only if the threat of an independent regulation is sufficiently powerful. When it occurs, soft capture leaves unchanged the cost of the supervision agency but it decreases the quality of information since firms introduce additional bias in their messages. Soft capture thus unambiguously decreases the welfare.

In a formal model of soft capture (Agrell and Gautier, 2010), we show that soft capture might be tolerated at the equilibrium if the quality of the biased information produced by the firm is high enough relative to the quality of information (potentially) produced

\footnotetext{
18 This effect is analogous to the results obtained in lobbying models (Cf. Austen-Smith and Wright, 1992): a lobbyist would only invest in costly information transmission provided the [regulator] enjoys a sufficiently low cost of independent information acquisition, or else the message would be discarded by default as non-informative.
} 
by the regulator. This implies that the importance of the bias introduced by the firm is directly linked to the treat exerted by the regulator. An under-staffed regulator with limited capabilities for gathering and processing information is likely to receive considerably biased industry input. Conversely, a regulator that is able to produce high quality information, that is highly damaging for the firm's rent, is likely to receive more accurate information (but still biased) from the firm. Maintaining high-level regulators remains important even if the political principal may tolerate capture and participation of the industry in the regulatory process. When the threat exerted by the regulator is not strong enough, the industry may be able to provide information that, at the end, leads to an ineffective regulation.

Facing this form of capture, it is thus essential to have highly skilled regulators. Even if the regulator remains 'a regulator as being', it forces the firm to produce not too biased information. Multiplying and diversifying the sources of information might be another path to prevent capture. If it is known that regulators are likely to accept cooperative inputs from the industry, additional sources of information might turn out to be useful. Guerriero (2011) documents that rate reviews for regulated US electricity distributors are organized as quasi-judicial hearings where all the interested parties (firms, customers...) have the opportunity to bring information to the regulatory commission (PUC). Rate reviews are thus less dependent on the regulator's ability to gather information from the industry. Parties are thus advocate of their interest and multiple sources of biased information may mitigate the problem created by capture ${ }^{19}$.

\section{An illustrating example}

The Occupational Safety and Health Administration (OSHA) is responsible for the regulation, monitoring and enforcement of workplace health and safety in the USA under the Occupational Safety and Health Act of 1970. The economic and social importance of the regulation is paramount, directly affecting about 130 million employees in USA (2010) and the workplace conditions, routines and equipment at about 9 million establishments (2009). Despite its importance, the literature only lists a single case of attempted corruption of OSHA inspectors (US v. Chmielewski, 1999), the amount of which was modest $(\$ 2,000)$.

However, the regulatory endowment has remained constant or even slightly decreased in absolute terms (-12\% in staff fte between 1975 and 2009), whereas the numbers of employees and establishments to monitor have increased by $90 \%$ and $128 \%$, respectively. As seen in Figure 2, the number of establishments to be regulated vastly outnumber the staff, radically increasing the potential workload.

The development of new regulations at OSHA is de facto based on reediting of material as "national consensus standards", developed by "trade or professional associations for the practices, systems, processes, or raw materials of their members"(Hamilton, note 13, 1978). The independent development of safety standards at OSHA is infrequent (two new standards promulgated between 1992 and 2000) and slow (four to seven years, cf. Shapiro and Rabinowitz, 2000). Regulatory rule making in occupational safety at OSHA is based on three analysis steps: determination of significant risk, technological

\footnotetext{
${ }^{19}$ Dewatripont and Tirole (1999).
} 
feasibility analysis and economic feasibility analysis. Given the weak resources for data collection, the initial step is often delayed or ineffective, potentially through the allocation of inspections to sites. The economic analysis is largely based on information commissioned by regulated firms or industry associations, in essence private standards that are forwarded to be promulgated as regulatory standards.

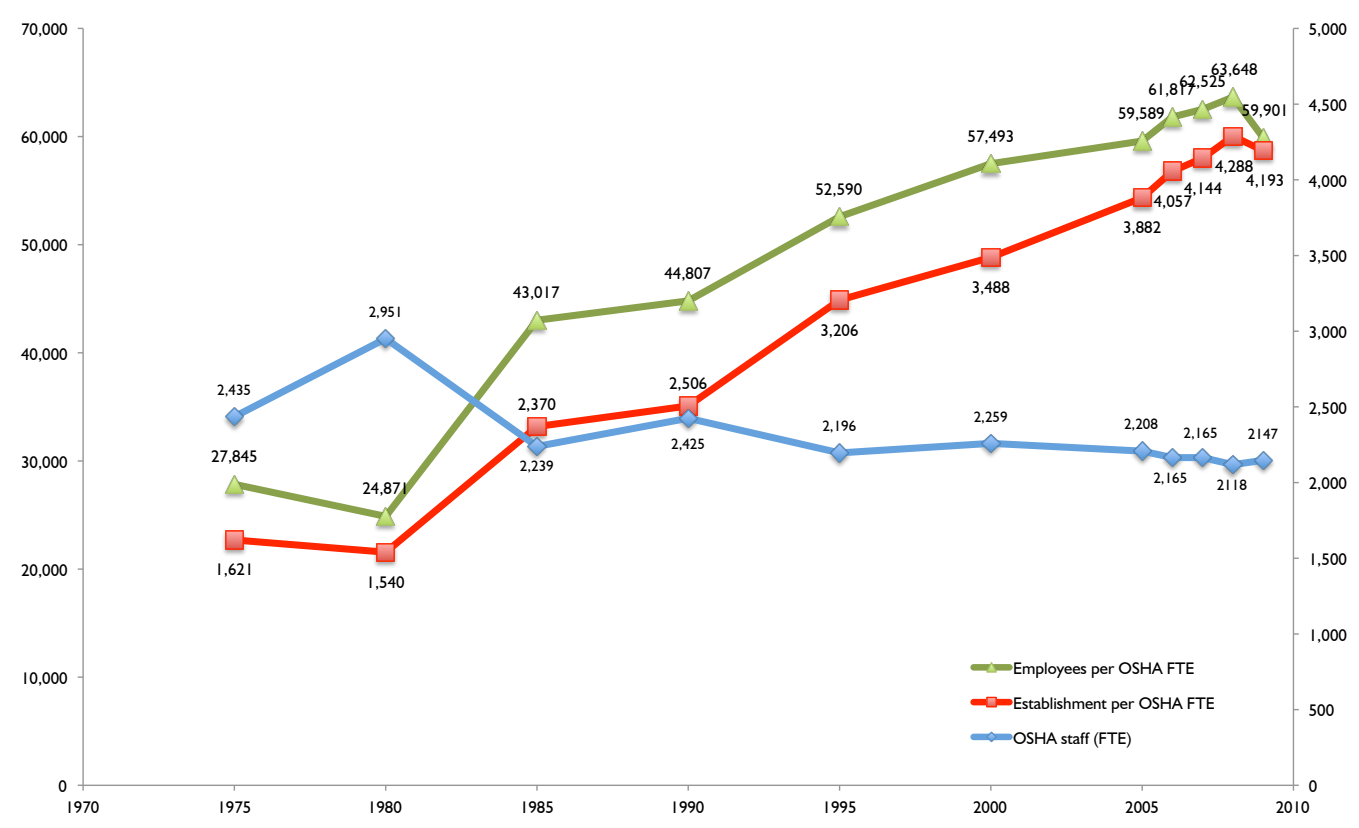

Figure 2: OSHA staff (FTE), employees under OSHA regulation per OSHA staff (FTE), establishments under OSHA regulation per OSHA staff (FTE). Source: OSHA (2011) and BLS (2005-2011)

The underlying information has been found to be systematically biased in an evaluation made by the US Congress (1995), implying adopted standards have more generous thresholds for employers and lower requirements for detection and abatement. E.g. in the standards for Vinyl Chloride (Oct 4, 1974, 39 FR 35890), OSHA relied on industry consultants' estimate of $1,000 \mathrm{M} \$$ in compliance costs. Actual spending in equipment, and incremental operating cost is around 228 - $278 \mathrm{M} \$$. (US Congress, 1995). The report documents similar findings for the exposure regulations for cotton dust, lead, ethylene oxide and formaldehyde, as well as for the operating regulations for grain handling, mechanical power presses and powered platforms for building maintenance. In addition, the technical feasibility analysis overestimates the time and instances affected by changes, hampering any application. The resulting regulations are not only weaker than those of international counterparts, they are also considerably more difficult to enforce by the regulator. An example for the OSHA enforcement: from 85.539 safety violations in 2003, only 404 were considered 'willful' and eligible for the highest criminal sanctions (Barstow, 2003). The outcome is striking: from a reported 2,197 workplace fatalities in 1982-2002, 1,242 were investigated by OSHA, thereof finally referring 119 
cases for legal prosecution, resulting in nine convictions to prison for the employer. Most investigations were dropped already at reporting, the rest from ambiguities in the regulation (Barstow, 2003). The resulting dismal enforcement record of OSHA, combined with very moderate fines ${ }^{21}$ for 'willful' violations of the standards renders the regulator relatively harmless to the regulated sector.

It is important to note that the highest officer in OSHA, the Assistant Secretary of Labor for Occupational Safety and Health, unlike the administration's staff, is directly appointed by the President and does not benefit from the statue of a civil servant. This specific conditions allows a casual test of the 'revolving door' hypothesis, as the direct capture could be exercised by the submitting bodies through later employment in e.g. associations or employer's organizations. However, the evidence is inconclusive: only two of the 12 past Assistant Secretaries since the creation of OSHA have obtained managerial positions in private industry, with five remaining in public service or research. Further, detailed analysis of the rulings from OSHA reveals that the 'soft capture' occurred already after a few years of existence and was well established in 1978 (Hamilton, 1978). Hence, the continued state of 'soft capture' in OSHA could be seen more as a structural response to a situation where the political endorsement of the regulatory activity is low or uncertain in combination with low independence of the regulatory supervisor. It seems plausible that the regulatory function of OSHA could have been implemented more effectively with the similar federal staff numbers if redirected to regulatory design and monitoring and enforcement were left to civil enforcement ${ }^{22}$. However, faced with the prospects of confronting industry with stringent labor regulations and potentially large civil lawsuits, the regulators seem to prefer the self-enforcing industry endorsement in the regulatory design stage while maintaining a relatively undisputed (yet ineffective) monitoring activity as the visible information processing to the political principal.

Remains to investigate whether the 'soft capture' in this case is welfare decreasing. Although the USA naturally benefits from the same occupational safety development as in the rest of the industrialized world, data shows (Figure 3) that the improvement rate 1998-2007 is slower than for a comparative market, EU-25, and stagnating at the end of the period. The absolute level of fatal accidents per 100,000 employees is also higher than in EU-25, indicating a continuing problem.

\section{Concluding remarks}

Regulatory capture is a composite phenomenon that has multiple expressions and causes. In this paper we address a specific type, direct legal capture by the regulated firm, that we claim to be one of the most common scenarios. Our relatively intuitive model of 'soft capture' is based on self-enforced collusion between the firm, providing biased information for free, and the regulator, using this information in its regulation

\footnotetext{
${ }^{21}$ The monetary fines have been increased once during 1971-2010. Maximum fine for 'willful' violation of safety standards, potentially leading to death of employees is $\$ 7,000$. Maximum penalty for death caused by willful negligence of workplace safety is $\$ 70,000$. The average OSHA penalty is $\$ 1,000$, normally even deadly accidents receive small penalties (median initial penalty claimed by OSHA for accidents with death involved was $\$ 5,700$ in 2007). Source: Testimony by Assistant Secretary David Michels to the US House of Representatives, March 16, 2010.

${ }^{22}$ Currently the case for environmental regulation, e.g. the Clean Water Act.
} 
rather than providing costly internal information processing. It differs from the conventional models of capture in the setup and the empirical conclusions.

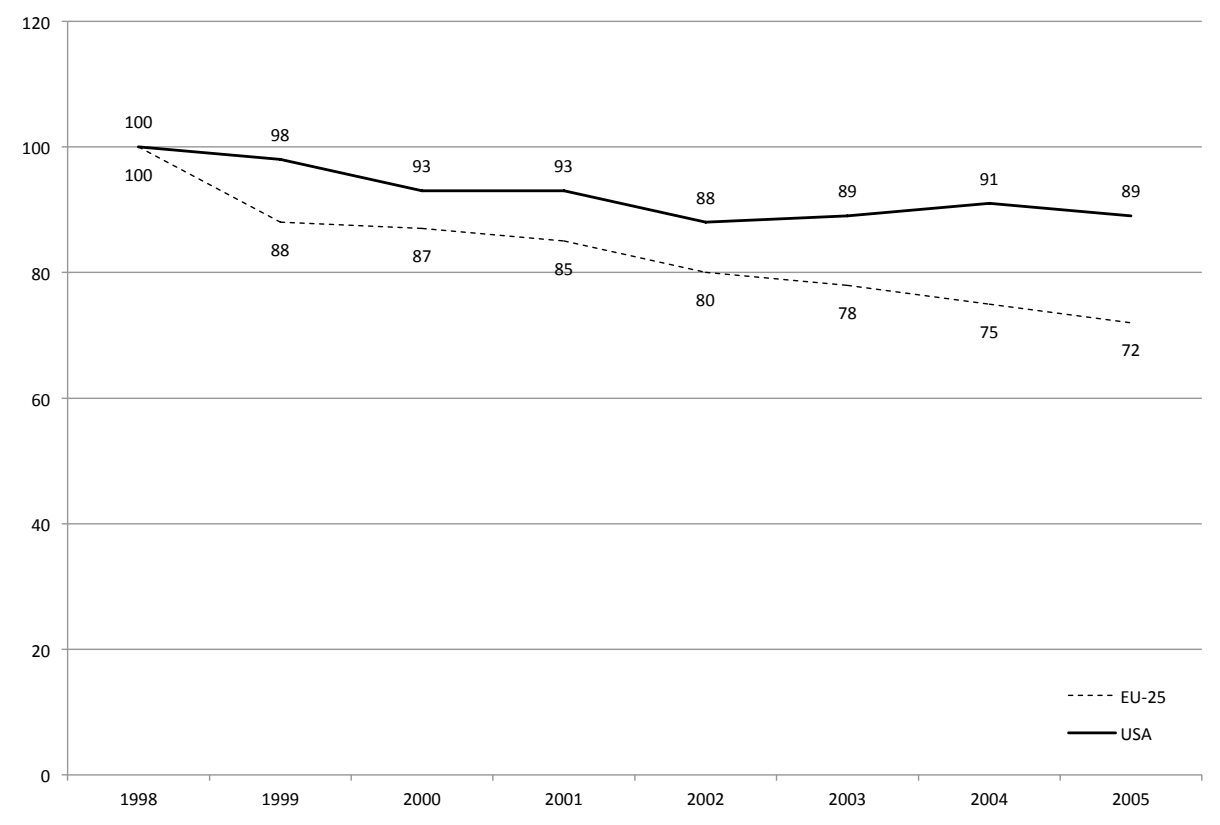

Figure 3: Development of the number of fatal workplace accidents per 100,000 employees in USA and EU-25, $1998=100$. Source: AFL-CIO (2011, p. 72), EUROSTAT (2011).

First, whereas the conventional model assumes that the regulator is offered a monetary award in exchange for blocking information transmission to the political principal, our model is based on a congruence of interests without side contracting and with information processing in equilibrium.

Second, the positive conjectures resulting from the conventional theories would either predict full capture in presence of generalized transfers of information rents to the regulators or implementations of collusion-proof mechanisms based on delegation of welfare objectives to the regulator.

Our model predicts a prevalence of soft capture in equilibrium without rent transfer but with transfer of processed information from firms to the regulator. The damages caused by capture are proportional to the cost of information processing for the regulators (or reciprocally, the precision they can obtain for a given budget). The industry is indeed likely to transmit more biased information or more favorable proposals when the regulator has a low capacity to process information by itself.

An analysis of the OSHA, a major federal regulatory agency in USA confirms the positive conjectures of our model while no evidence is found for the two conventional conjectures. OSHA operates a regulation where the rule-making largely is based on 
industry-based material that is biased and resulting in instructions with weak enforcement power. The regulator has maintained a constant budget since its conception and its resources are foremost devoted to monitoring at the expense of regulation and enforcement. No evidence of high-level corruption, nor of revolving doors between firms and the regulator, has been found. Hence, we have at hand an example of soft capture. Qualitatively, lowered information processing costs, e.g. by higher endowment in qualified staff or budgets for external independent experts, would result in lower incidence of soft capture, detected as a more stringent regulation and higher enforcement precision.

The previous 'paradox of capture' has thus found one possible explanation along with several empirically verifiable hypotheses. Further empirical work about regulatory capture, both longitudinal and across sectors, is necessary to fully validate with validity of this and alternative models in understanding this socially important phenomenon.

An interesting extension of the model can be made for the case of direct capture by other stakeholders, such as downstream clients, since the regulator merely reacts to submitted information from any source. Although the authors ignore such examples in actual regulatory practice in Europe, plausibly due to problems of information asymmetry and internal cost allocation within the stakeholder collective, the previously mentioned US-type intervenor process at the Public Utility Commissions is analogous. In this manner, an "information contest" between advocates representing different interest groups might be a more effective way to collect information than a single source of information captured by the industry ${ }^{23}$.

The example notwithstanding, there is no claim of generality emanating from the model. Both the literature (cf. Makkai and Braithwaite, 1992) and the anecdotal evidence above suggest that the relations between the political principal and the supervisor, the independence give to the latter and the implication of the former in the decision making are important in understanding the internal and external functioning of regulation. In particular, for the OSHA case, the implicit acceptance by the political principal (US Government) of the soft capture over a longer time period constitutes, without ever becoming an official endorsement, an indication of indirect capture rigged by the political principal and the regulated firm. Moreover the methodological complexities involved in empirically estimating the overall welfare effects of regulatory capture, yet alone sector regulation and its means, are significant and hampering comparative analysis.

\section{References}

AFL-CIO (2011), 'Death of the Job: A National and State-by-State Profile of Worker Safety and Health in the United States', 20th Edition, American Federation of Labor \& Congress of Industrial Organizations, Washington DC.

Agrell, P. J. and A. Gautier (2010), 'A Theory of Soft Capture', Discussion Paper 2010/84, CORE, Université catholique de Louvain.

\footnotetext{
${ }^{23}$ Dewatripont and Tirole (1999) show that even a nonpartisan independent agent may be less effective for collecting information than competing advocates.
} 
Austen-Smith, D. and J. Wright (1992), 'Competitive Lobbying for a Legislator's Vote,' Social Choice and Welfare, 9(3), 229-257.

Barstow, D. (2003), 'U.S. Rarely Seeks Charges for Deaths in Workplace', New York Times , Dec. 22, 2003.

BLS (2005-2011), 'Bureau of Labor Statistics Occupational Injuries and Illnesses Report for the years 1994-2010'.

Che, Y.-K. (1995), 'Revolving Doors and the Optimal Tolerance for Agency Collusion', RAND Journal of Economics, 26(3), 378-397.

Dal Bó , E. (2006), 'Regulatory Capture: A Review', Oxford Journal of Economic Policy, 22(2), 203-225.

Dewatripont, M. and J. Tirole (1999), 'Advocates', Journal of Political Economy, 107(1), 1-39.

Estache, A. and L. Wren-Lewis (2011), 'What Anti-Corruption Policies can Learn from Regulation Theory' in S. Rose-Ackerman and T. Soreide (eds), The International Handbook of Anti-Corruption Economics (Vol. II), Edward Elgar.

EC (2009), 'Causes and circumstances of accidents at work in the EU', Luxembourg: Office for Official Publications of the European Communities.

EUROSTAT (2011), 'Fatal Accidents at Work', statistics available at http://epp.eurostat.ec.europa.eu/.

Guerriero, C. (2011), 'Accountability in Government and Regulatory Policies: Theory and Evidence', University of Amsterdam.

Hamilton, R. W. (1978), 'The Role of Nongovernmental Standards in the Development of Mandatory Federal Standards Affecting Safety or Health', Texas Law Review, 56(8), 1329.

Laffont, J.-J. and J. Tirole (1991), 'The Politics of Government Decision-Making: A Theory of Regulatory Capture', The Quarterly Journal of Economics, 106(4), 1089-1127.

Laffont, J.-J. and J. Tirole (1993), 'A Theory of Incentives in Procurement and Regulation,' MIT Press.

Leaver, C. (2009), 'Bureaucratic minimal squawk behavior: Theory and evidence from regulatory agencies', American Economic Review, 99(3), 572-607.

Makkai, T. and J. Braithwaite (1992), 'In and out of the Revolving Door: Making Sense of Regulatory Capture', Journal of Public Policy, 12(1), 61-78.

Martimort, D. (1999), 'The Life Cycle of Regulatory Agencies: Dynamic Capture and Transaction Costs', Review of Economic Studies, 66(4), 929-947. 
OSHA (2009) 'Reflections on OSHA's History', U.S. Department of Labor, Occupational Safety and Health Administration (OSHA).

OSHA (2011), 'FY 2012 Congressional Budget Justification: Occupational Safety and Health Administration', U.S. Department of Labor, Occupational Safety and Health Administration (OSHA).

Salant, D. (1995), 'Behind the Revolving Doors: A New View on Public Utility Regulation', RAND Journal of Economics, 26(3), 362-377.

Shapiro, S. A. and R. Rabinowitz (2000), 'Voluntary Regulatory Compliance in Theory and practice: The Case of OSHA', Administrative Law Review, 52(1), 97-155.

Smith, R. and M. Söderberg (2010), 'Public Interest versus Regulatory Capture in the Swedish Electricity Market', Journal of Regulatory Economics, 38(3), 292-312.

Thatcher, M. (2002), 'Regulation after Delegation: Independent Regulatory Agencies in Europe', Journal of European Public Policy, 9(6), 954-972

Tirole, J. (1986), 'Hierarchies and Bureaucracies: On the Role of Capture in Organizations', Journal of Law and Economic Organization, 2(2), 181-214.

U.S. Congress (1995), 'Gauging Control Technology and Regulatory Impacts in Occupational Safety and Health: An Appraisal of OSHA's Analytic Approach', Report OTA-ENV-635, Office of Technology Assessment, Washington, DC: U.S.

US v. Chmielewski (1999), Case No. 99-1773 in US Court of Appeals, 7th Circuit, F. 3d, vol. $196,893$. 


\section{Recent titles \\ CORE Discussion Papers}

2011/29. Ana MAULEON, Elena MOLIS, Vincent J. VANNETELBOSCH and Wouter VERGOTE. Absolutely stable roommate problems.

2011/30. Nicolas GILLIS and François GLINEUR. Accelerated multiplicative updates and hierarchical als algorithms for nonnegative matrix factorization.

2011/31. Nguyen Thang DAO and Julio DAVILA. Implementing steady state efficiency in overlapping generations economies with environmental externalities.

2011/32. Paul BELLEFLAMME, Thomas LAMBERT and Armin SCHWIENBACHER. Crowdfunding: tapping the right crowd.

2011/33. Pierre PESTIEAU and Gregory PONTHIERE. Optimal fertility along the lifecycle.

2011/34. Joachim GAHUNGU and Yves SMEERS. Optimal time to invest when the price processes are geometric Brownian motions. A tentative based on smooth fit.

2011/35. Joachim GAHUNGU and Yves SMEERS. Sufficient and necessary conditions for perpetual multi-assets exchange options.

2011/36. Miguel A.G. BELMONTE, Gary KOOP and Dimitris KOROBILIS. Hierarchical shrinkage in time-varying parameter models.

2011/37. Quentin BOTTON, Bernard FORTZ, Luis GOUVEIA and Michael POSS. Benders decomposition for the hop-constrained survivable network design problem.

2011/38. J. Peter NEARY and Joe THARAKAN. International trade with endogenous mode of competition in general equilibrium.

2011/39. Jean-François CAULIER, Ana MAULEON, Jose J. SEMPERE-MONERRIS and Vincent VANNETELBOSCH. Stable and efficient coalitional networks.

2011/40. Pierre M. PICARD and Tim WORRALL. Sustainable migration policies.

2011/41. Sébastien VAN BELLEGEM. Locally stationary volatility modelling.

2011/42. Dimitri PAOLINI, Pasquale PISTONE, Giuseppe PULINA and Martin ZAGLER. Tax treaties and the allocation of taxing rights with developing countries.

2011/43. Marc FLEURBAEY and Erik SCHOKKAERT. Behavioral fair social choice.

2011/44. Joachim GAHUNGU and Yves SMEERS. A real options model for electricity capacity expansion.

2011/45. Marie-Louise LEROUX and Pierre PESTIEAU. Social security and family support.

2011/46. Chiara CANTA. Efficiency, access and the mixed delivery of health care services.

2011/47. Jean J. GABSZEWICZ, Salome GVETADZE and Skerdilajda ZANAJ. Migrations, public goods and taxes.

2011/48. Jean J. GABSZEWICZ and Joana RESENDE. Credence goods and product differentiation.

2011/49. Jean J. GABSZEWICZ, Tanguy VAN YPERSELE and Skerdilajda ZANAJ. Does the seller of a house facing a large number of buyers always decrease its price when its first offer is rejected?

2011/50. Mathieu VAN VYVE. Linear prices for non-convex electricity markets: models and algorithms.

2011/51. Parkash CHANDER and Henry TULKENS. The Kyoto Protocol, the Copenhagen Accord, the Cancun Agreements, and beyond: An economic and game theoretical exploration and interpretation.

2011/52. Fabian Y.R.P. BOCART and Christian HAFNER. Econometric analysis of volatile art markets.

2011/53. Philippe DE DONDER and Pierre PESTIEAU. Private, social and self insurance for long-term care: a political economy analysis.

2011/54. Filippo L. CALCIANO. Oligopolistic competition with general complementarities.

2011/55. Luc BAUWENS, Arnaud DUFAYS and Bruno DE BACKER. Estimating and forecasting structural breaks in financial time series.

2011/56. Pau OLIVELLA and Fred SCHROYEN. Multidimensional screening in a monopolistic insurance market.

2011/57. Knud J. MUNK. Optimal taxation in the presence of a congested public good and an application to transport policy.

2011/58. Luc BAUWENS, Christian HAFNER and Sébastien LAURENT. Volatility models. 


\section{Recent titles}

\section{CORE Discussion Papers - continued}

2011/59. Pierre PESTIEAU and Grégory PONTHIERE. Childbearing age, family allowances and social security.

2011/60. Julio DÁVILA. Optimal population and education.

2011/61. Luc BAUWENS and Dimitris KOROBILIS. Bayesian methods.

2011/62. Florian MAYNERIS. A new perspective on the firm size-growth relationship: shape of profits, investment and heterogeneous credit constraints.

2011/63. Florian MAYNERIS and Sandra PONCET. Entry on difficult export markets by Chinese domestic firms: the role of foreign export spillovers.

2011/64. Florian MAYNERIS and Sandra PONCET. French firms at the conquest of Asian markets: the role of export spillovers.

2011/65. Jean J. GABSZEWICZ and Ornella TAROLA. Migration, wage differentials and fiscal competition.

2011/66. Robin BOADWAY and Pierre PESTIEAU. Indirect taxes for redistribution: Should necessity goods be favored?

2011/67. Hylke VANDENBUSSCHE, Francesco DI COMITE, Laura ROVEGNO and Christian VIEGELAHN. Moving up the quality ladder? EU-China trade dynamics in clothing.

2011/68. Mathieu LEFEBVRE, Pierre PESTIEAU and Grégory PONTHIERE. Measuring poverty without the mortality paradox.

2011/69. Per J. AGRELL and Adel HATAMI-MARBINI. Frontier-based performance analysis models for supply chain management; state of the art and research directions.

2011/70. Olivier DEVOLDER. Stochastic first order methods in smooth convex optimization.

2011/71. Jens L. HOUGAARD, Juan D. MORENO-TERNERO and Lars P. ØSTERDAL. A unifying framework for the problem of adjudicating conflicting claims.

2011/72. Per J. AGRELL and Peter BOGETOFT. Smart-grid investments, regulation and organization.

2012/1. Per J. AGRELL and Axel GAUTIER. Rethinking regulatory capture.

\section{Books}

J. HINDRIKS (ed.) (2008), Au-delà de Copernic: de la confusion au consensus ? Brussels, Academic and Scientific Publishers.

J-M. HURIOT and J-F. THISSE (eds) (2009), Economics of cities. Cambridge, Cambridge University Press.

P. BELLEFLAMME and M. PEITZ (eds) (2010), Industrial organization: markets and strategies. Cambridge University Press.

M. JUNGER, Th. LIEBLING, D. NADDEF, G. NEMHAUSER, W. PULlEYBLANK, G. REINELT, G. RINALDI and L. WOLSEY (eds) (2010), 50 years of integer programming, 1958-2008: from the early years to the state-of-the-art. Berlin Springer.

G. DURANTON, Ph. MARTIN, Th. MAYER and F. MAYNERIS (eds) (2010), The economics of clusters Lessons from the French experience. Oxford University Press.

J. HINDRIKS and I. VAN DE CLOOT (eds) (2011), Notre pension en heritage. Itinera Institute.

M. FLEURBAEY and F. MANIQUET (eds) (2011), A theory of fairness and social welfare. Cambridge University Press.

V. GINSBURGH and S. WEBER (eds) (2011), How many languages make sense? The economics of linguistic diversity. Princeton University Press.

\section{CORE Lecture Series}

D. BIENSTOCK (2001), Potential function methods for approximately solving linear programming problems: theory and practice.

R. AMIR (2002), Supermodularity and complementarity in economics.

R. WEISMANTEL (2006), Lectures on mixed nonlinear programming. 